\title{
LEVANTAMENTO FLORÍSTICO DAS ESPÉCIES UTILIZADAS NA ARBORIZAÇÃO DE PRAÇAS NO MUNICÍPIO DE CRATO, CE
}

\author{
Antonio Carlito Bezerra dos Santos ${ }^{1}$; Maria Arlene Pessôa da Silva ${ }^{2}$; Renata Kelly Dias Souza ${ }^{1}$
}

\begin{abstract}
Resumo
O objetivo deste trabalho foi realizar um levantamento das espécies utilizadas na arborização de praças no município de Crato - CE. Foram listados e identificados os indivíduos arbóreos existentes nas cinco principais praças do município. Na ocasião, foram observadas a diversidade de espécies e sua incidência. Material botânico em estágio reprodutivo foi coletado para posterior identificação. Os exemplares foram herborizados e depositados no Herbário Caririense Dárdano de Andrade-Lima da Universidade Regional do Cariri. As identificações foram realizadas por comparação com material previamente identificado pertencente às coleções do referido herbário e com auxílio de bibliografia especializada. Nas cinco praças trabalhadas, foram registrados 277 indivíduos distribuídos em 13 famílias, 15 gêneros e 18 espécies, das quais, Ficus retusa var. nitida (Thunb.) Miq. foi a de maior representatividade com 109 indivíduos. Das espécies registradas, Mangifera indica L., Eugenia malaccensis L. e Annona squamosa L. são reconhecidamente frutíferas. A maioria das espécies arbóreas cultivadas em praças no município são exóticas. Apesar de nossa flora contar com centenas de espécies de grande beleza e qualidade paisagística, ainda não existe uma utilização efetiva das mesmas na arborização urbana.
\end{abstract}

Palavras-chave: Arborização, Praças, Espécies Exóticas, Crato.

\section{FLORISTIC SURVEY OF THE SPECIES USED IN AFFORESTATION OF SQUARE IN THE CITY OF CRATO, CE}

\begin{abstract}
The objective of this study was to survey the species used in afforestation of squares in the city of Crato - CE. Were listed and identified individual trees existing in the five main squares of the city. On occasion, we observed the diversity of species and incidence. Botanical material in reproductive stage was collected for further identification. The specimens were herbalized and deposited in the Herbarium Caririense Dardano de Andrade-Lima Regional University of Cariri. The identifications were made by comparison with previously identified material belonging to the herbarium collections of this and with the aid of literature. In the five squares worked, there have been 277 individuals in 13 families, 15 genera and 18 species, of which, Ficus retusa var. nitida (Thunb.) Miq. was the most representative of 109 individuals. Of the recorded species, Mangifera indica L., Eugenia malaccensis L. and Annona squamosa L. fruit are known. Most tree species grown in the city squares are exotic. Despite our flora count hundreds of species of great beauty and quality landscape, there is still no effective use of them in urban areas.
\end{abstract}

Keywords: Afforestation, Squares, Exotic Species, Crato.

\footnotetext{
${ }^{1}$ Programa de Pós-gradução em Bioprospecção Molecular da Universidade Regional do Cariri, Crato, Ceará, Brasil.

E-mail: carlitobio@hotmail.com

${ }^{2}$ Doutora em Fitotecnia pela Universidade Federal do Ceará - UFC. Professora Adjunta do Departamento de Ciências Biológicas da Universidade Regional do Cariri - URCA, Crato, Ceará, Brasil.
} 


\section{Introdução}

As cidades são constituídas, do ponto de vista físico, de espaços de interação urbana, espaços com construções e de espaços livres (CAVALHEIRO; DEL PICCHIA, 1992).

Richter (1981) afirma que o total dos espaços livres de uma cidade, de certa forma, é a somatória dos diversos elementos verdes e diferentes espaços livres isolados em assentamentos urbano-industriais e devem ser designados por Verde Urbano, incluindo o sistema de espaços livres, tanto os públicos, como os particulares.

A vegetação é um importante componente regulador da temperatura urbana, pois absorve com muito mais facilidade a radiação solar que é utilizada nos seus processos biológicos: fotossíntese $\mathrm{e}$ transpiração (GOMES; AMORIM, 2003).

A maior quantidade de vegetação implica na mudança do balanço de energia, devido à necessidade de as plantas absorverem o calor em função de seus processos vitais (LOMBARDO, 1985).

O homem está constantemente agindo sobre o meio ambiente, a fim de sanar suas necessidades e desejos. As ações sobre o meio ambiente podem afetar a qualidade de vida no planeta, assim como projetos arquitetônicos ou urbanísticos afetam as respostas dos seus usuários e moradores (OKAMOTO, 1996).

Segundo Maciel et al. (2008), a antropização caracteriza-se por ser um processo rápido e muitas vezes indiscriminado, que resulta na alteração da paisagem natural das regiões. Geralmente, esta paisagem é substituída pela urbanização ou pelo uso agrícola. Além da alteração da paisagem original, a intervenção antrópica também traz a introdução de espécies exóticas. Estas espécies são causadoras de diversos problemas de desequilíbrio ambiental, como a competição por nutrientes e abrigo com as espécies nativas da região.

Passos e Lopes Jr. (1998), acrescentam que a presença do verde em praças e jardins, em especial de espécies arbóreas, é fundamental, seja para criar áreas de microclimas, que atuam amenizando situações extremas, principalmente, as provocadas pelo excesso de espaços construídos e impermeabilizados, pela presença de poeira e de poluentes do ar, seja pela reciclagem do ar com a produção de oxigênio.

Nos grandes centros urbanos, as árvores têm um caráter essencial para a manutenção da qualidade de vida, pois proporcionam inúmeros benefícios para a comunidade existente. Elas melhoram a qualidade do ar; oferecem sombra e amenizam as altas temperaturas; servem de abrigo e fornecem alimentos aos animais; funcionam como barreira acústica; melhoram as condições do solo; valorizam os imóveis do ponto de vista estético e ambiental; caracterizam a beleza natural da cidade e representam valores culturais da memória histórica da mesma (MACIEL et al., 2008).

Dias (1996) afirma que conhecer as espécies mais adequadas para utilização na arborização, demanda conhecimento de características como: tamanho, frutificação, caducifólia, porte, forma do tronco, presença de espinhos, emissão de odores, agressividade das raízes, velocidade de crescimento, durabilidade, rusticidade, resistência à poluição, impacto de pedestres, pragas e doenças, resistência ao vento, à seca e etc.

Para Oliveira e Ferreira (2005), é preciso compatibilizar a arborização urbana e a prestação de serviços de utilidade pública, e isso somente é possível através de um planejamento da arborização prevendo o uso de espécies adequadas. A falta de planejamento acarreta prejuízos e riscos de acidentes, exigindo constantes podas, cortes drásticos e algumas vezes a eliminação das árvores.

A maioria das plantas arbóreas cultivadas em ruas, avenidas, praças e jardins da região do Cariri são de espécies exóticas oriundas de outras regiões e/ou países. Apesar de nossa flora contar com um considerável número de espécies de grande beleza e qualidade paisagística, ainda não foram descobertas por nossos jardineiros e paisagistas (SANTOS, 1999).

Este estudo visou realizar um levantamento florístico das espécies utilizadas na arborização de praças no município de Crato - CE, verificando suas vantagens e desvantagens, contribuindo dessa forma para a criação e o fortalecimento de mecanismos de planejamento da arborização urbana, aliados à conservação da biodiversidade local.

\section{Material e Métodos}

\section{- Área de Estudo}

O estudo foi realizado nas seguintes praças: Alexandre Arraes (Praça do Bicentenário); Praça da Sé; Praça Siqueira Campos; Praça Juarez Távora (Praça São Vicente) e Praça Francisco Sá (Praça dos Pombos) na cidade de Crato. Município, localizado no extremo Sul do Estado do Ceará (Figura 1), região do Cariri, com uma latitude de $07^{\circ} 14$ ' $34^{\prime \prime}$ Sul e a 
uma longitude de $30^{\circ} 24^{\prime} 34^{\prime \prime}$ Oeste, a pouco mais de $500 \mathrm{Km}$ de distância de Fortaleza.

Segundo o senso de 2007 do Instituto Brasileiro de Geografia e Estatística (IBGE), o município do Crato possui uma área de $1.009 \mathrm{~km}^{2} \mathrm{e}$ uma população de 111.198 habitantes (IBGE, 2009).

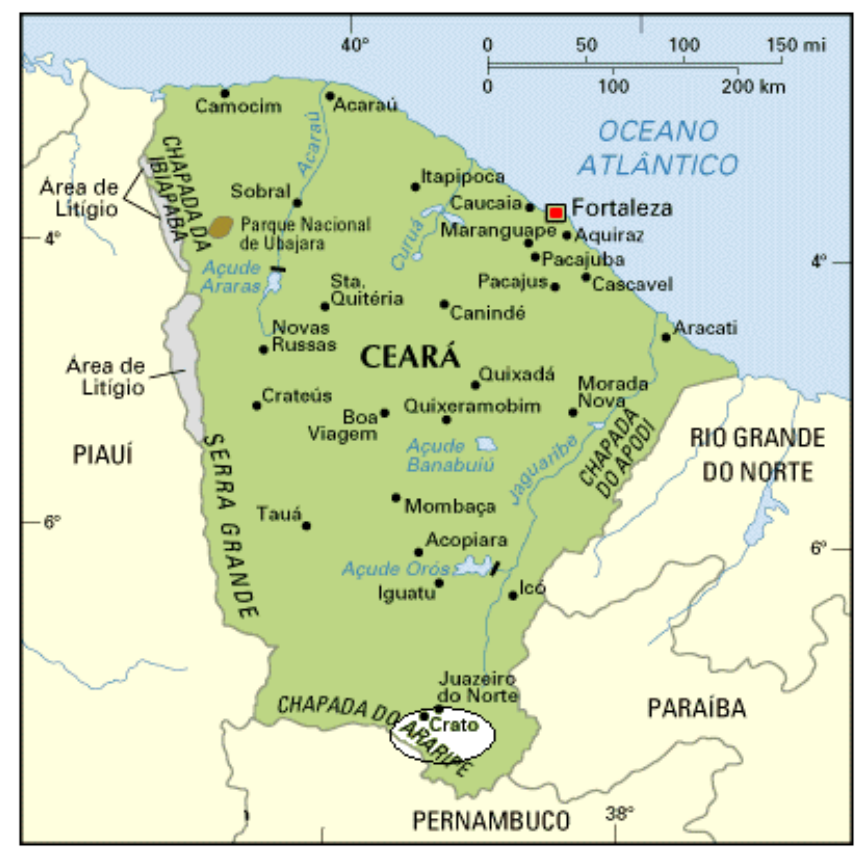

Figura 1- Mapa do Ceará localizando a cidade de Crato Fonte: www.technet1.org/.../brasil/mapaceara.htm

\section{- Levantamento Florístico}

Para o levantamento florístico e identificação botânica das espécies, coletou-se material em estágio reprodutivo (flor e/ou fruto).

O Material Botânico foi herborizado e incorporado ao acervo do Herbário Caririense Dárdano de Andrade-Lima (HCDAL) da Universidade Regional do Cariri - URCA.

As identificações foram realizadas por comparação com material previamente identificado pertencente às coleções do referido herbário e com auxílio de bibliografia especializada.

\section{Resultados e Discussão}

Foram registrados 277 indivíduos distribuídos em 13 famílias, 15 gêneros e 18 espécies, indicados na Tabela 1. Dentre estes se destacam pela frequência as seguintes espécies: Ficus retusa var. nitida (109), Roystonea oleracea (59), Licania tomentosa (30) e Tabebuia impetiginosa (26). Oliveira e Ferreira (2005), pesquisando a arborização urbana de Cáceres, MT, observaram à ocorrência destas mesmas espécies sendo utilizadas para fins ornamentais.

Tabela 1- Origem e relação das espécies arbóreas existentes em cinco praças no município de Crato, CE. 2009.

\begin{tabular}{llll}
\hline \multicolumn{1}{c}{ Nome Popular } & \multicolumn{1}{c}{ Família } & \multicolumn{1}{c}{ Nome Científico } & \multicolumn{1}{c}{ Origem } \\
\hline Mangueira & Anacardiaceae & Mangifera indica L. & Exótica \\
Pinha & Annonaceae & Annona squamosa L. & Exótica \\
Palmeira-imperial & Arecaceae & Roystonea oleracea (Jacq.) O.F. Cook & Exótica \\
Palmeira & Arecaceae & Washingtonia filifera (Linden) Wendl. & Exótica \\
Pau-d'arco & Bignoniaceae & Tabebuia impetiginosa (Mart. ex DC.) Standl. & Nativa \\
Munguba & Bombacaceae & Pachira aquatica Aubl. & Exótica \\
Flamboyam-de-jardim & Caesalpiniaceae & Caesalpinia pulcherrima (L.) Sw. & Exótica \\
Pau-ferro & Caesalpiniaceae & C. leiostachya (Benth.) Ducke & Nativa
\end{tabular}

Continua... 
SANTOS, A.C.B.; SILVA, M.A.P.; SOUZA, R.K. Levantamento florístico das espécies utilizadas na arborização de praças no município de Crato, CE.

Tabela 1 - Continuação...

\begin{tabular}{llll}
\hline \multicolumn{1}{c}{ Nome Popular } & \multicolumn{1}{c}{ Família } & \multicolumn{1}{c}{ Nome Científico } & \multicolumn{1}{c}{ Origem } \\
\hline Canafístula & Caesalpiniaceae & C. ferrea Mart. & Nativa \\
Castanhola & Combretaceae & Terminalia catappa L. & Exótica \\
Oiti & Crysobalanaceae & Licania tomentosa (Benth.) Fritsch & Nativa \\
Nim-indiano & Meliaceae & Azadirachta indica A. Juss. & Exótica \\
Orelha-de-negro & Mimosaceae & Enterolobium contortisiliquum (Vell.) & Nativa \\
Pau-brasil & Mimosaceae & Morong & Nativa \\
Figueira & Moraceae & Ficus retusa var. nitida (Thunb.) Miq. & Exótica \\
Jambo & Myrtaceae & Eugenia malaccensis L. & Exótica \\
Eucalipto & Myrtaceae & Eucalyptus globulus Labill. & Exótica \\
Brasileirinho & Papilionaceae & Erythrina indica Lam.var. picta Hort. & Exótica \\
\hline
\end{tabular}

Das espécies registradas, três produzem frutos comestíveis: $M$. indica, E. malaccensis e $A$. squamosa. Dias (1996) e Santos e Teixeira (2001), não recomendam o plantio de árvores frutíferas comerciais em vias públicas e dá preferência para árvores de crescimento rápido, pela dificuldade que uma árvore adulta proporciona aos atos de vandalismo. Em contra partida, Coletto et al. (2008) e Dias e Costa (2008), afirmam que o uso de plantas frutíferas nativas na arborização é recomendado sob o ponto de vista ambiental para propiciar a atração da fauna silvestre para a cidade.

A maioria das espécies observadas não são nativas, mantendo-se como prática comum na arborização das praças do município o emprego de espécies exóticas. Dias e Costa (2008), afirmam que as espécies nativas, além de benefícios ao quadro urbano, como adaptação, atração da avifauna e propagação de espécies, beneficia também a preservação das mesmas por meio de uma ornamentação de vias somando-se as utilidades e conservação, bem como, desperta a população para a importância da flora nativa.

\section{- Distribuição das Espécies}

\section{Praça Alexandre Arraes}

A Praça Alexandre Arraes (Figura 2) apresentou a maior diversidade de espécies, tendo sido observados 65 indivíduos, com prevalência das espécies T. impetiginosa (26), $P$. aquatica (12) e $F$. retusa var. nitida (10), e as demais espécies variaram de um a cinco indivíduos.

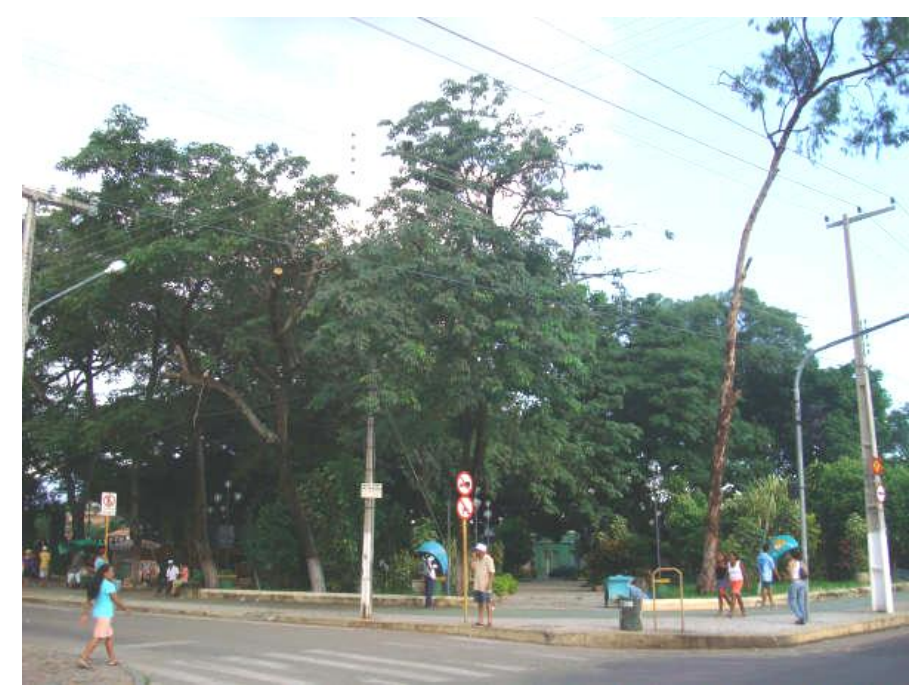

Figura 2- Aspecto geral da Praça Alexandre Arraes.

\section{Praça da Sé}

A Praça da Sé (Figura 3) apresentou 69 indivíduos com apenas duas espécies arbóreas: $R$. oleracea e L. tomentosa com 44 e 25 indivíduos, respectivamente. 


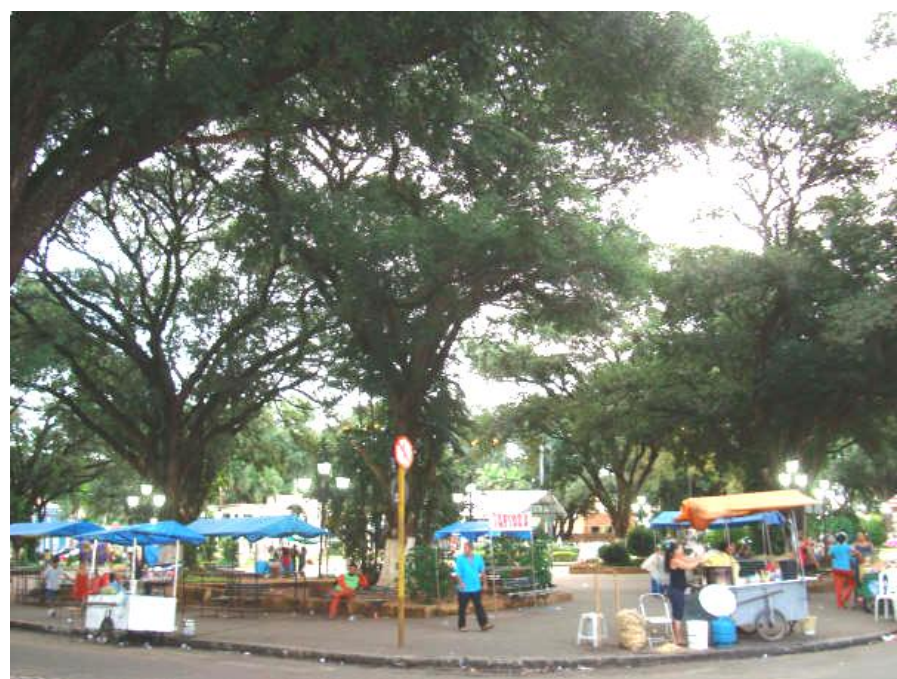

Figura 3- Aspecto geral da Praça da Sé.

\section{Praça Siqueira Campos}

Na Praça Siqueira Campos (Figura 4) foi encontrado o menor número de indivíduo (20), sendo a espécie $F$. retusa var. nitida (12) que mais se destacou em número de indivíduos.

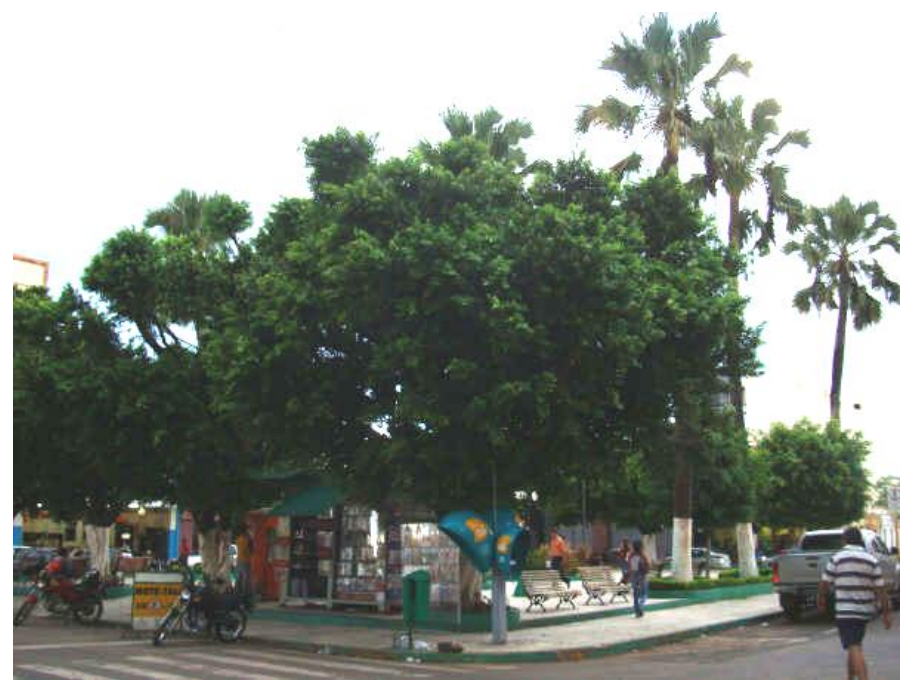

Figura 4- Aspecto geral da Praça Siqueira Campos.

\section{Praça Francisco de Sá}

Na Praça Francisco de Sá (Figura 5) registrouse o maior número de indivíduos (103). A espécie mais representativa em número de indivíduos foi $F$. retusa var. nitida (87).

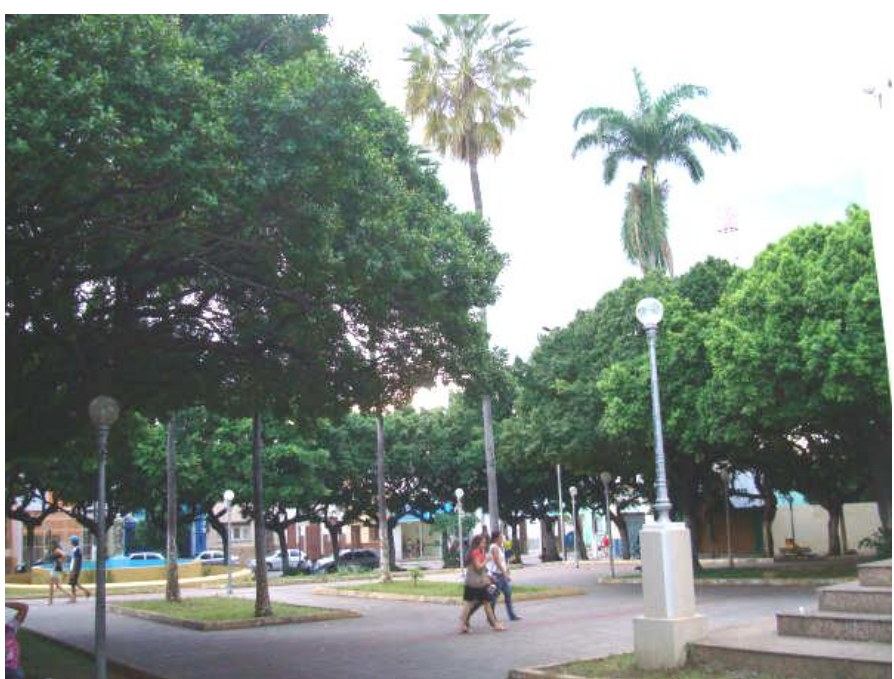

Figura 5- Aspecto geral da Praça Francisco de Sá

\section{Praça Juarez Távora}

Na Praça Juarez Távora (Figura 6) registrou-se 21 indivíduos, alocados em seis espécies. Nesta praça verificou-se a ocorrência de três espécies frutíferas: M. indica, E. malaccensis e A. squamosa. A espécie mais representativa em número de indivíduos foi $E$. malaccensis (8).

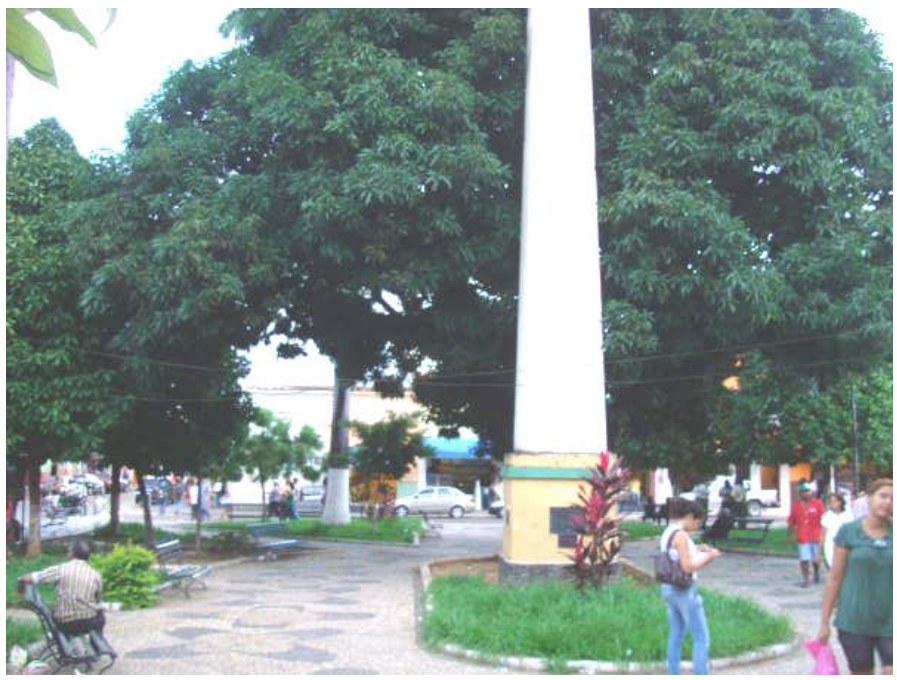

Figura 6- Aspecto geral da Praça Juarez Távora

\section{Conclusões}

A espécie mais representativa em número de indivíduos nas cinco Praças trabalhadas foi $F$. retusa var. nitida.

A arborização do município privilegia espécies exóticas, uma vez que, poucas espécies nativas são utilizadas na arborização. 
A transformação do espaço urbano, a partir de um bom planejamento de arborização, é possível desde que, Instituições de Ensino e Pesquisa, Sociedade Civil Organizada e Poder Público Municipal, estejam aliados, no intuito de promover melhores condições ambientais para os moradores dos centros urbanos, permitindo assim, um planejamento continuado de uma política urbana para o setor. O conhecimento da composição florística possibilita avaliar a flora local visando sua utilização entre outras coisas na arborização de praças e ruas.

\section{Referências}

CAVAlHEIRO, F.; DEL PICCHIA, P.C.D. Áreas Verdes: Conceitos, Objetivos e Diretrizes para o Planejamento. In: Anais do $1^{\circ}$ Congresso Brasileiro Sobre Arborização Urbana $/ 4^{\circ}$ Encontro Nacional Sobre Arborização Urbana; 13-18 de Setembro de 1992; Hotel Porto do Sol. Vitória - ES; 1992.

COLETTO, E.P.; et al. Diagnóstico da Arborização das Vias Públicas do Município de Sete de Setembro - RS. Revista SBAU, v.3, n.2. p.110-122, 2008.

DIAS, J.; COSTA, D. Sugestões de Espécies Arbóreas Nativas Ocorrentes no Sul do Estado do Paraná para Fins Ornamentais. In: $\mathbf{8}^{\circ}$ Encontro de Iniciação Científica e $\mathbf{8}^{\circ}$ Mostra de Pós Graduação; Paraná: FAFUV, 2008.

DIAS, R. A importância da arborização urbana. In: Seminário de Arborização Urbana no Rio de Janeiro; 1996; Rio de Janeiro: UFRJ, 1996.

GOMES, M.A.S.; AMORIM, M.C.C.T. Arborização e conforto térmico no espaço urbano: Estudo de caso nas praças públicas de Presidente Prudente (SP).
Revista Caminhos de Geografia. v. 7, n.10, p. 94106, 2003.

IBGE. Cidades. Disponível em: <http://www.ibge.com.br/cidadesat/topwindow.htm? 1> Acesso em: 12 maio 2009.

LOMBARDO, M.A. Ilha de Calor nas Metrópoles: o exemplo de São Paulo. São Paulo: Ed. Hucitec., 1985.

MACIEL, J.L.; et al. Educação Ambiental como ferramenta para a manutenção da arborização urbana de Porto Alegre - RS. In: Congresso Brasileiro de Arborização Urbana; Manaus: SBAU, 2008.

OKAMOTO, J. Percepção ambiental e comportamento. São Paulo: Plêiade, 1996.

OLIVEIRA, I.L.; FERREIRA, A.R. Arborização Urbana, Alteração das Paisagens e Biodiversidade, melhoria de qualidade de vida dos moradores de Cáceres, MT. In: Anais do VIII Congresso Iberoamericano de Extensão Universitária. Rio de Janeiro: UFRJ, 2005.

PASSOS, M.M.; LOPES JR., W.M. Algumas considerações sobre a vegetação urbana no município de Bauru-SP. Revista Geográfica, 1998.

RICHTER, G. Handbuch Stadtgrun. Munique; Viena; Zurique. BLV. 1981. 319 p.

SANTOS, C.A. Levantamento das Espécies Arbóreas que compõem a Urbanização do Município de Juazeiro do Norte - CE. Monografia de Especialização em Botânica. Crato: URCA, 1999.

SANTOS, N.R.Z. ; TEIXEIRA, I.F. Arborização de vias públicas: ambiente $X$ vegetação. Santa Cruz do Sul, RS: Instituto Souza Cruz, 2001. 